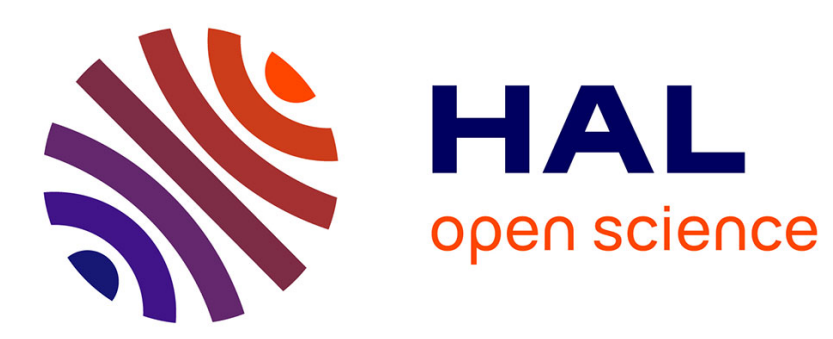

\title{
3D-Modelling of polycrystalline silicon solar cells
}

J. Dugas, J. Oualid

\section{To cite this version:}

J. Dugas, J. Oualid. 3D-Modelling of polycrystalline silicon solar cells. Revue de Physique Appliquée, 1987, 22 (7), pp.677-685. 10.1051/rphysap:01987002207067700 . jpa-00245596

\section{HAL Id: jpa-00245596 https://hal.science/jpa-00245596}

Submitted on 1 Jan 1987

HAL is a multi-disciplinary open access archive for the deposit and dissemination of scientific research documents, whether they are published or not. The documents may come from teaching and research institutions in France or abroad, or from public or private research centers.
L'archive ouverte pluridisciplinaire HAL, est destinée au dépôt et à la diffusion de documents scientifiques de niveau recherche, publiés ou non, émanant des établissements d'enseignement et de recherche français ou étrangers, des laboratoires publics ou privés. 


\title{
3D-Modelling of polycrystalline silicon solar cells
}

\author{
J. Dugas and J. Oualid
}

Laboratoire des Matériaux et Composants Semiconducteurs, Ecole Nationale Supérieure de Physique de Marseille, Domaine Universitaire de St-Jérôme, 13397 Marseille Cedex 13, France

(Reçu le 29 septembre 1986, accepté le 8 décembre 1986)

\begin{abstract}
Résumé. - Nous nous intéressons à l'influence des joints de grains sur les principaux paramètres qui caractérisent les photopiles en silicium polycristallin. Nous calculons la vitesse de recombinaison effective à l'aide d'une méthode auto-consistante qui tient compte de la courbure du quasi-niveau de Fermi des minoritaires dans la région de charge d'espace associée au joint et dans la région quasi neutre des grains. En nous basant sur cette étude, nous avons tracé à l'aide d'un modèle à 3 dimensions une série d'abaques qui permettent de prévoir les variations des propriétés photovoltaïques en fonction des grandeurs caractéristiques d'un matériau semiconducteur polycristallin : dimension $g$ des grains, longueur de diffusion $L_{\mathrm{n}}$ et dopage $N_{\mathrm{A}}$ des grains et vitesse de recombinaison interfaciale $S$ aux joints de grains. Nous montrons que le rendement peut être augmenté en ajustant le dopage de la base des photopiles. Le dopage optimum est donné en fonction de la densité des états d'interface et de la dimension des grains. Enfin, nous définissons une longueur de diffusion effective dans un matériau polycristallin prenant en compte la recombinaison aux joints de grains. Cette longueur de diffusion effective peut être mesurée par la méthode de la phototension de surface (SPV). Nous en avons déterminé les variations en fonction de $S, L_{\mathrm{n}}$ et $g$. Cette grandeur permet de prévoir une valeur approchée des propriétés photovoltaïques.
\end{abstract}

\begin{abstract}
This work is concerned with the effect of grain boundaries (gb) on the main parameters which characterize polycrystalline silicon solar cells. The variation with illumination of the grain boundary effective recombination velocity has been calculated by means of a self-consistent procedure which takes into account the bending of the minority carrier quasi-Fermi level in the space-charge region and in the gb quasi-neutral region. Abaci have been plotted which allow to predict the photovoltaic properties as a function of the characteristic quantities of a polycrystalline material: grain size $g$, diffusion length $L_{\mathrm{n}}$ and doping concentration in the grains and interfacial recombination velocity $S$ at the grain boundaries. It is shown by means of a 3D-model that the conversion efficiency can be enhanced by optimizing the doping concentration of the base of the cells ; the optimum doping level and the related efficiency are given as a function of grain size for different interface state densities. Finally, an effective diffusion length taking into account the gb recombination is introduced. This effective diffusion length can be measured by the Surface PhotoVoltage (SPV) method. Its variation as a function of $S, L_{\mathrm{n}}$ and $g$ have been determined. This quantity allows to forecast approximate values of the photovoltaic properties.
\end{abstract}

\section{Introduction.}

Polycrystalline silicon is different from monocrystalline silicon essentially due to the presence of grain boundaries ( $\mathrm{gb}$ ) which act as recombination centres for excess carriers $[1,2]$ and which contribute to a marked decrease of solar cell efficiencies [3-6]. The gb recombination of the excess carriers takes place via the gb interface states which can be due to the dangling bonds, the dislocations, or the impurities segregated or diffused into the grain boundaries. This gb activity is well defined by an interfacial recombination velocity.
As the interface states are generally charged, a band bending appears near a gb characterized by a barrier height $E_{\mathrm{gb}}$ and a space charge region (SCR) of width $W_{\mathrm{gb}}$ which lies on each side of the gb (Fig. 1). The high electric field in this space charge region drifts the minority carriers towards the gb and contributes to an enhancement of their recombination. Therefore, from a practical point of view, it is interesting to consider an effective recombination velocity [7] which takes into account the presence of the gb barrier height. The charge of the gb interface states depends on the level of excitation which, in the case of a solar cell, is related to the intensity of 


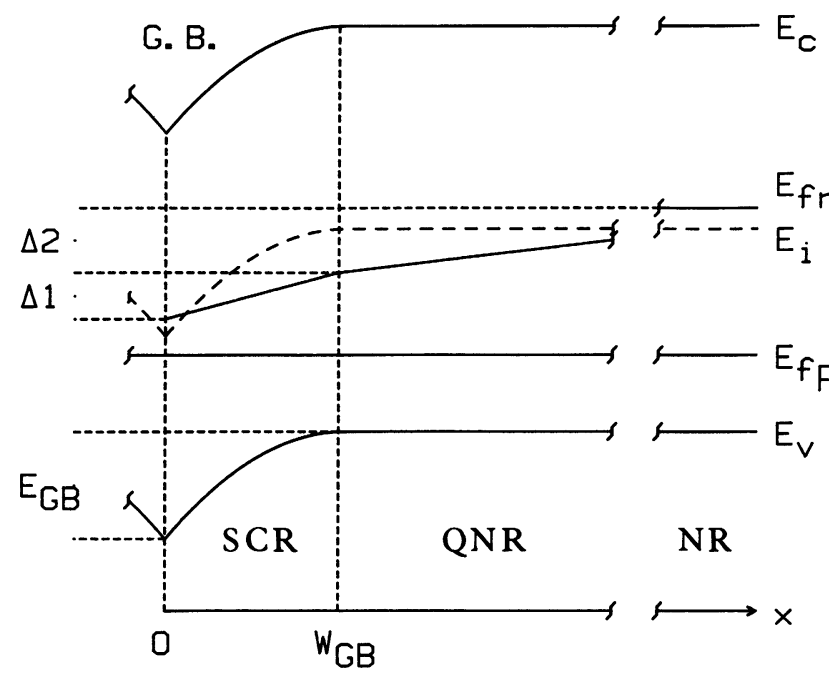

Fig. 1. - Band diagram at the vicinity of a grain boundary in a p-type illuminated semiconductor. SCR : gb space charge region; QNR : quasi-neutral region ; NR : neutral region.

the incident light. The excess carriers due to the light tend to saturate the gb interface states so that the $\mathrm{gb}$ barrier height [8] and consequently the effective recombination velocity [9] decrease as the excitation level increases.

The numerical results presented here are concerned with interface states distributed with a density $N_{\mathrm{t}}$ per unit area on a single energy level lying at midgap, which is the most effective for carrier recombination. The model has been extended to different interface state distributions [10]. The charge of states is given by the half-filled band model (HFB) [11] in which a pair of states is associated with each dangling bond; this model is often used in the case of undissociated dislocations [12] and can be applied to low angle gb which can be considered as a line of dislocations.

Before studying the behaviour of such a polycrystalline silicon solar cell, by means of a 3D-model developed in section 2, we have established, in section 1, the variation of the gb barrier height $E_{\mathrm{gb}}$ and of the subsequent effective recombination velocity $S_{\text {eff }}$ under different excitation levels for different interface state densities and doping concentrations. Section 3 is devoted to the definition of an effective diffusion length $L_{\text {eff }}$ which takes into account the recombination at the grain boundaries. Modelling this effective diffusion length is particularly interesting since it can be measured by the Surface Photo Voltage method and is able to give an estimation of the photovoltaic performances of a polycrystalline material.

\section{Grain boundary under illumination.}

In the present work, the bending of the minority carrier quasi-Fermi level in the gb space charge region $\left(\Delta_{1}\right)$ and in the gb quasi-neutral region $\left(\Delta_{2}\right)$ has been taken into account. In contrast to the analysis given by Seager [9] based partially on the thermoionic emission model, we have used only the Shockley-Read-Hall theory for the self-consistent determination of the gb barrier height $E_{\mathrm{gb}}$ and the effective' recombination velocity $S_{\text {eff. }}$.

Figure 1 gives a schematic representation of the variation of the energy bands and the quasi-Fermi levels with the distance $x$ at a gb under illuminated conditions for a p-type semiconductor. In this model, we assume that :

a) Under low and medium excitation conditions, the quasi-Fermi level of the majority carriers $E_{\mathrm{Fp}}$ is flat everywhere but the quasi-Fermi level of the minority carriers $E_{\mathrm{Fn}}$ is allowed to vary in the space charge region $\left(-W_{\mathrm{gb}}<x<W_{\mathrm{gb}}\right)$ as well as in the quasi-neutral region as proposed by Seager [9].

b) The occupation probability $f$ (under non equilibrium conditions) and the carrier recombination rate $U_{\mathrm{B}}$ are given by the Shockley-Read-Hall expressions [13].

c) The excitation is uniform in the base of the solar cell. This is actually the case only for long wavelength illumination for which the absorption coefficient is nearly constant within the base. The excitation level is characterized by the difference between the quasi-Fermi levels, $E_{\mathrm{Fn}}-E_{\mathrm{Fp}}$, in the neutral region of the grains.

On the basis of these assumptions, the gb barrier height $E_{\mathrm{gb}}$ and the effective recombination velocity are determined self-consistently.

The variations of the bendings $\Delta_{1}$ and $\Delta_{2}$ as a function of the excitation level $E_{\mathrm{Fn}}-E_{\mathrm{Fp}}$ in the bulk of the grains are shown in figure 2. The bending of the minority carrier quasi-Fermi level is always much larger in the quasi-neutral region than in the $\mathrm{gb}$ space charge region as obtained also by Seager [9]. In this figure, it is exhibited that $\Delta_{1}$ may be neglected at very low or very high excitation, but $\Delta_{2}$ is always quite significant. So, the minority carrier quasiFermi level can be assumed to be flat in the gb space charge region and with a less degree of validity in the quasi-neutral region only in these limiting cases. The flat minority carrier quasi-Fermi level approximation may be adopted only at very low excitation due to the small minority carrier flux or at high excitation due to the decrease of the gb effective recombination velocity. $\Delta_{1}$ and $\Delta_{2}$ are maximum for a critical excitation level which depends on the gb interface state distribution and on the doping concentration in the grains.

The variation of the effective recombination velocity $S_{\text {eff }}$ as a function of the excitation level is shown in figure 3 for different interface state densities $N_{\mathrm{t}}$ and for different doping levels $N_{\mathrm{A}}$. For a given 


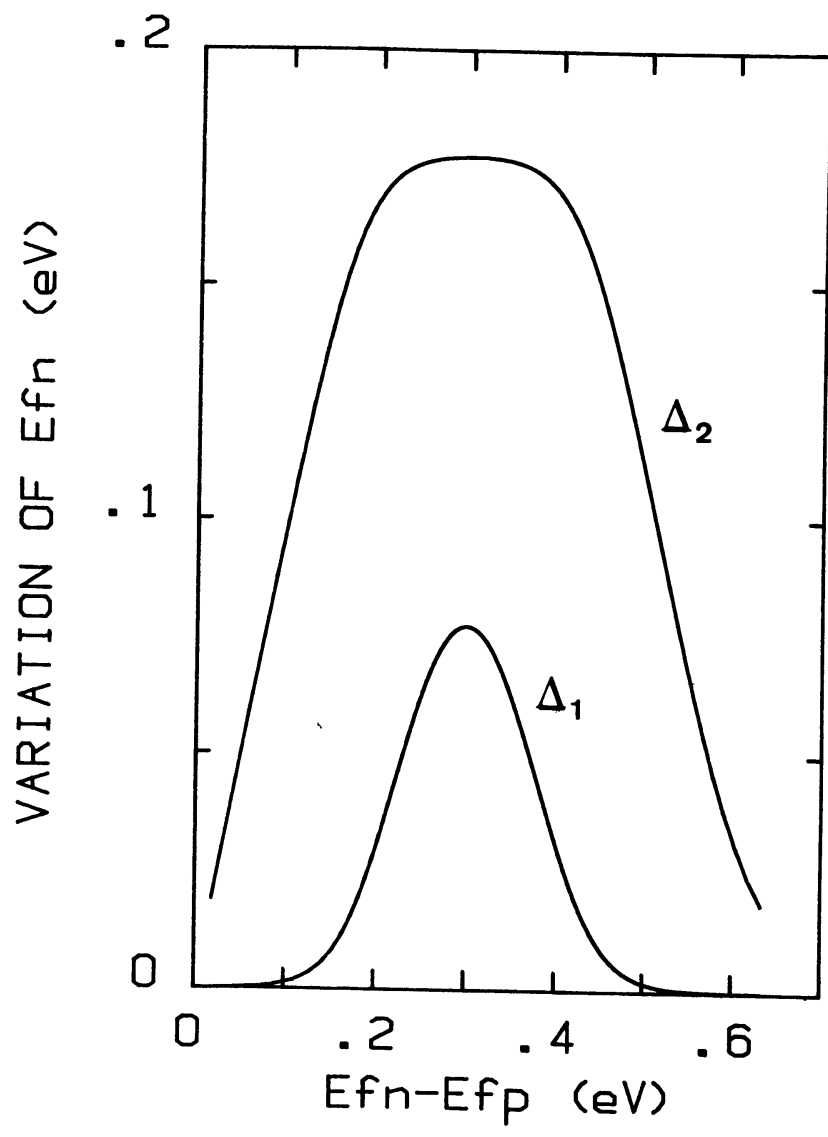

Fig. 2. - Bendings of the minority carrier quasi-Fermi level in the gb space charge region $\left(\Delta_{1}\right)$ and in the quasineutral region of the adjacent grain $\left(\Delta_{2}\right) v s$ the excitation level. Doping concentration $N_{\mathrm{A}}=10^{16} \mathrm{~cm}^{-3}$; diffusion length $L_{\mathrm{n}}=50 \mu \mathrm{m}$.

excitation, $S_{\text {eff }}$ (and $E_{\mathrm{gb}}$ ) increases always with $N_{\mathrm{t}}$ (Fig. 3a) whereas $S_{\text {eff }}$ (and $E_{\mathrm{gb}}$ ) decreases as the doping level becomes sufficiently large (Fig. 3b). We have demonstrated that the recombination velocity $S_{\text {eff }}$ cannot exceed a limiting value which is about the half of the thermal velocity $v_{\text {th }}$ [13]. The asymptotic behaviour of $S_{\text {eff }}$ towards $v_{\text {th }} / 2$ when the density of states is large is obvious in figure 3 . It is worth noting

Fig. 3. - Variation of the effective recombination velocity $S_{\text {eff }}$ with the excitation level

a) for different interface state densities.

$$
N_{\mathrm{A}}=10^{16} \mathrm{~cm}^{-3} \text {. }
$$

1) $N_{\mathrm{t}}=4 \times 10^{11} \mathrm{~cm}^{-2}$; 2) $N_{\mathrm{t}}=6 \times 10^{11} \mathrm{~cm}^{-2}$; 3) $N_{\mathrm{t}}=8 \times 10^{11} \mathrm{~cm}^{-2}$; 4) $N_{\mathrm{t}}=10^{12} \mathrm{~cm}^{-2}$; 5) $N_{\mathrm{t}}=5 \times$ $10^{12} \mathrm{~cm}^{-2}$.

b) for different doping concentrations.

$$
N_{\mathrm{t}}=10^{12} \mathrm{~cm}^{-2} \text {. }
$$

1) $N_{\mathrm{A}}=10^{15} \mathrm{~cm}^{-3}$;2) $N_{\mathrm{A}}=3 \times 10^{15} \mathrm{~cm}^{-3}$; 3) $N_{\mathrm{A}}=$ $10^{16} \mathrm{~cm}^{-3}$; 4) $N_{\mathrm{A}}=3 \times 10^{16} \mathrm{~cm}^{-3}$; 5) $N_{\mathrm{A}}=10^{17} \mathrm{~cm}^{-3}$. REVUE DE PHYSIQUE APPLIQUÉE. - T. 22, $\mathbf{N}^{\bullet} 7$, JUILLET 1987
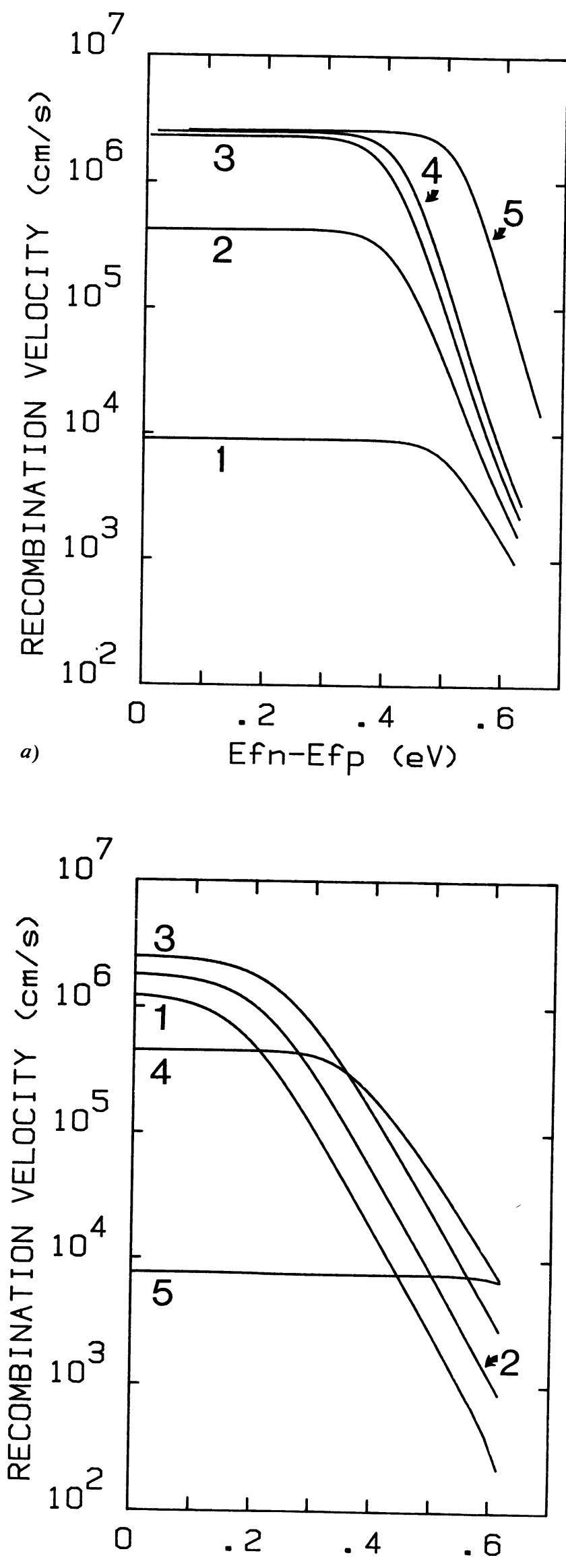

b) 
that $S_{\text {eff }}$ remains constant up to an excitation level $E_{\mathrm{fn}}-E_{\mathrm{fp}}=0.5 \mathrm{eV}$ corresponding to about the maximum power point of a solar cell under AM1 illumination. This result allows to simplify significantly the analysis developed in the next section.

\section{Solar cell 3D-model.}

2.1 HYPOTHESES. - The grains have been assumed to have homogeneous properties (doping concentration, minority carrier mobility, recombination lifetime and difusion length), and to be fibrously oriented, i.e. all the grain boundaries are perpendicular to the front and back surfaces and consequently to the junction. For the sake of simplicity, we have assumed a square cross section (side g) for the grains (Fig. 4). The analysis can be easily extended to a rectangular grain shape [14], e.g. in the case of ribbons.

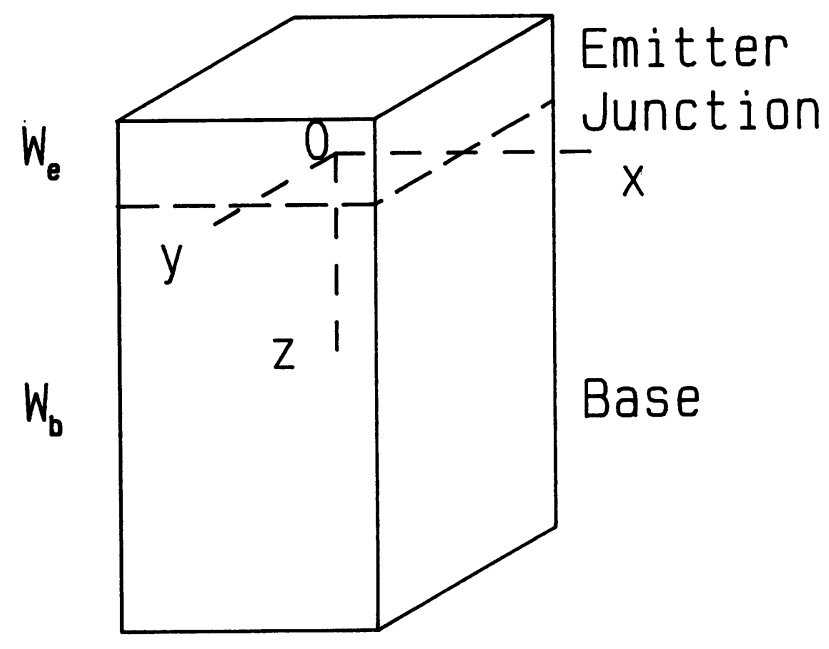

\section{Ohmic Contact}

Fig. 4. - Model of a square grain (side g). $W_{\mathrm{e}}$ and $W_{\mathrm{b}}$ are the widths of the emitter and the base of the cell, respectively. The origin of the axes is in the junction plane, the $x$ - and $y$-axes are perpendicular to the grain boundaries, the $z$-axis is perpendicular to the junction.

As the emitter region is heavily doped, $S_{\text {eff }}$ is very small in this region as shown above and the gb recombination in the emitter is therefore negligible [15]. We have also neglected the gb recombination in the junction space charge region since we have shown in a previous work [16] that the gb barrier height is strongly reduced in this region, in agreement with the results of Green [17]. Therefore, the contributions of these two regions have been calculated using the classical one-dimensional model [18]. The series resistance due to the base material, which varies as the doping concentration is varied, has been taken into account but limitations which might be introduced by the series resistances due to the emitter, the grid or the back ohmic contact have not been taken into account since they depend strongly on the process involved. Therefore, the results given in this paper must be considered as an upper limit of what can be expected from polycrystalline silicon solar cells.

The photocurrent, for a given illumination and for short-circuit conditions, is derived from the excess minority carrier concentration $\Delta n$ in a grain which can be written as an infinite series [14]. Similar expressions are used for the dark minority carrier concentration needed to compute the dark saturation current [10].

2.2 PhOtovoltaic QUANTITIES. - The photovoltaic quantities under study, short-circuit photocurrent, dark saturation current, open circuit voltage, fill factor and efficiency, have been computed and plotted as a function of one of the following macroscopic quantities [10] :

- the effective recombination velocity $S_{\text {eff }}$ defined in the previous section, which characterizes the electronic activity of the grain boundaries;

- the diffusion length $L_{\mathrm{n}}$, which characterises the recombination of the minority carriers in the grains ;

- the grain size $g$ which is obviously the fundamental parameter for polycrystalline materials.

It has been found that the degradation of the photovoltaic properties, with respect to a monocrystalline silicon cell, is small as the effective recombination velocity is less than $10^{3} \mathrm{~cm} / \mathrm{s}$ whereas a strong variation is observed in the range $10^{3}<S_{\text {eff }}<$ $10^{5} \mathrm{~cm} / \mathrm{s}$, particularly a drastic increase of the dark saturation current. Larger effective recombination velocities do not affect significantly more the photovoltaic properties.

Increasing the bulk diffusion length $L_{\mathrm{n}}$ provides an enhancement of the photovoltaic properties up to a saturation value which depends on the grain size. As an example, the conversion efficiency has been plotted in figure 5 as a function of the ratio $g / 2 L_{\mathrm{n}}$ for different values of the bulk diffusion length $L_{\mathrm{n}}$. It can be seen that increasing the grain size more than ten times the bulk diffusion length does not improve significantly the conversion efficiency. In the case of a diffusion length $L_{n}=$ $100 \mu \mathrm{m}$, which is usually measured in polycrystalline silicon wafers like Silso-Wacker or CGE-Polyx, conversion efficiencies greater than $14 \%$ can be expected if the grain size is greater than $2 \mathrm{~mm}$.

These results confirm that, in a gettering process, preference must be given to the reduction of the gb activity for «small» grain materials and to the passivation of intragrain defects for « large » grain 


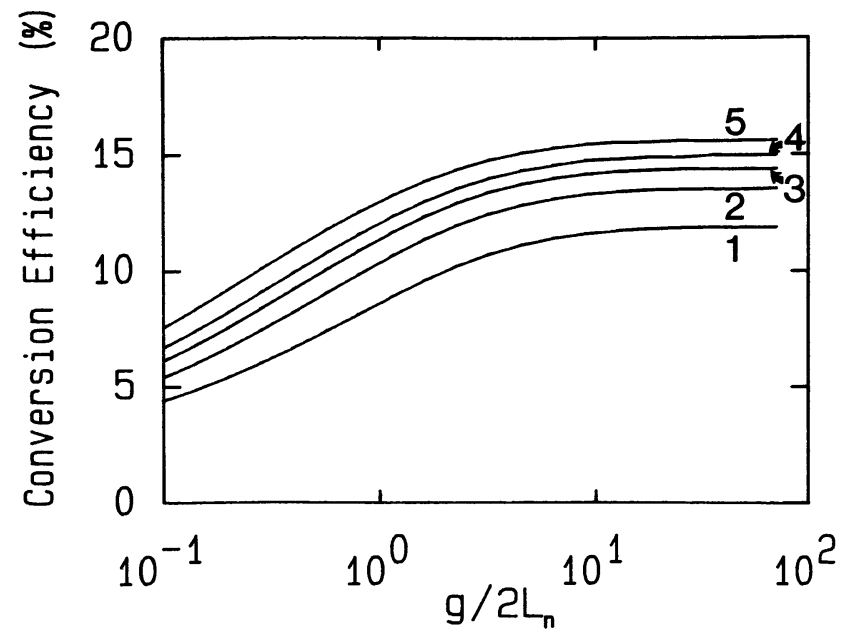

Fig. 5. - Variation of the conversion efficiency $v s$. the scaled grain size. $N_{\mathrm{A}}=10^{16} \mathrm{~cm}^{-3} ; S=10^{6} \mathrm{~cm} / \mathrm{s}$; base thickness : $500 \mu \mathrm{m}$. Bulk diffusion length :

1) $L_{\mathrm{n}}=25 \mu \mathrm{m}$; 2) $L_{\mathrm{n}}=50 \mu \mathrm{m}$; 3) $L_{\mathrm{n}}=75 \mu \mathrm{m}$; 4) $L_{\mathrm{n}}=100 \mu \mathrm{m}$; 5) $L_{\mathrm{n}}=150 \mu \mathrm{m}$.

materials, «small » and « large » being defined with respect to the diffusion length.

2.3 BASE DOPING CONCENTRATION INFLUENCE. Since an increase in the doping concentration level involves a reduction of the gb effective recombination velocity [15], it appears possible to achieve better photovoltaic performances by increasing the doping level in the grains. However, the mobility and lifetime and consequently the diffusion length of the minority carriers decrease as the doping level is increased. So, an optimum doping concentration can be found which must result from a compromise between the degradation of the bulk electronic properties and the reduction of the gb activity as the doping level is enhanced. Intragrain defects (deep levels introduced by dislocations or impurities) have not been taken into account but only the unavoidable effects due to the high doping level, scattering and Auger effect in particular. So, the minority carrier mobility can be represented by the relation :

$$
\mu_{n}=197+\frac{963}{1+\left(\frac{N_{\mathrm{A}}}{2.95 \times 10^{16}}\right)^{0.91}} \text { (CGS units) }
$$

derived from the curves given by Adler et al. [19] for single-crystal silicon. The minority carrier lifetime has been calculated from the relation given by Fossum [20] :

$$
\tau_{n}=\frac{1.7 \times 10^{-5}}{1+\frac{N_{\mathrm{A}}}{7.1 \times 10^{15}}} \text { (CGS units) }
$$

As the base doping level $N_{\mathrm{A}}$ is increased from
$10^{14} \mathrm{~cm}^{-3}$ to $10^{18} \mathrm{~cm}^{-3}$, the dark saturation current decreases monotonically from some $10^{-6} \mathrm{~mA} / \mathrm{cm}^{2}$ to some $10^{-10} \mathrm{~mA} / \mathrm{cm}^{2}$ [21], joining the value of a single-crystal cell for this doping level. Due to the lessening of the carrier diffusion length, the shortcircuit photocurrent $J_{\mathrm{ph}}$ decreases, except in a range of doping concentration where $S_{\text {eff }}$ decreases strongly. $J_{\text {ph }}$ is maximum for a doping concentration which depends on the grain size and on the interface state density [21].

The variation of the conversion efficiency as a function of the doping concentration is plotted in figure 6 for different grain sizes and for a large density of interface states. The maximum of the conversion efficiency is obtained for smaller doping concentrations and its amplitude is enhanced as the grain size is increased.

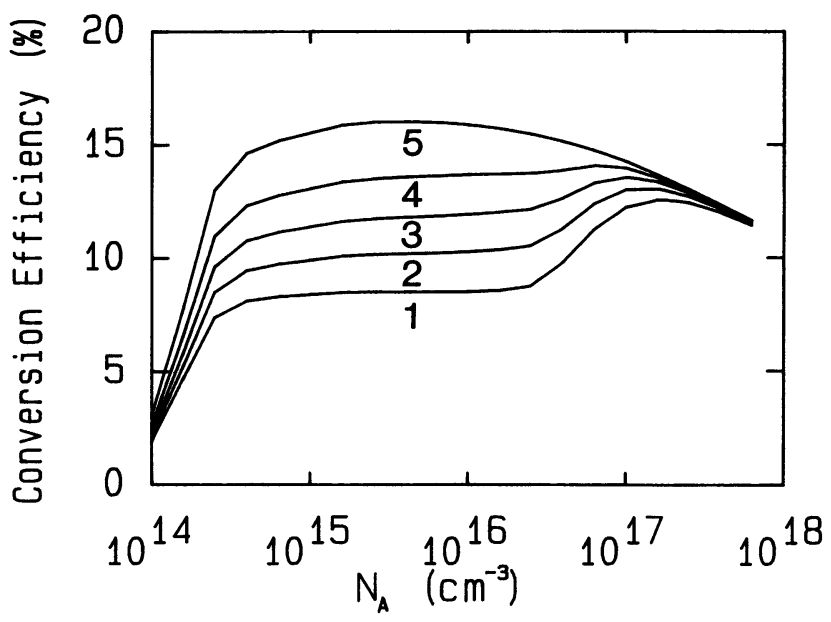

Fig. 6. - Variation of the conversion efficiency as a function of the base doping level, for different grain sizes : 1) $g=50 \mu \mathrm{m}$; 2) $g=100 \mu \mathrm{m}$; 3) $g=200 \mu \mathrm{m}$; 4) $g=500 \mu \mathrm{m} ; 5)$ single-crystal cell.

Base width : $W_{\mathrm{b}}=370 \mu \mathrm{m}$.

Emitter : n-type, $N_{\mathrm{D}}=5 \times 10^{19} \mathrm{~cm}^{-3}, W_{\mathrm{e}}=0.2 \mu \mathrm{m}$.

$$
N_{\mathrm{t}}=10^{12} \mathrm{~cm}^{-2} \text {. }
$$

Figure 7 gives the variation of the optimum doping concentration $N_{\mathrm{A} \text { opt }}$ as a function of the grain size, for different interface state densities. The computation has been limited to grain sizes in the range $35 \mu \mathrm{m}-2000 \mu \mathrm{m}$ : for greater grain sizes, the efficiency passes through a broad maximum so that its determination is very inaccurate and has no interest whereas for smaller grain sizes the present model is less adequate.

- the optimum doping concentration $N_{\mathrm{A} \text { opt }}$ is all the greater that the grain size $g$ is smaller, whatever the interface state density $N_{\mathrm{t}}$. $N_{\mathrm{t}}^{\bullet}$. 


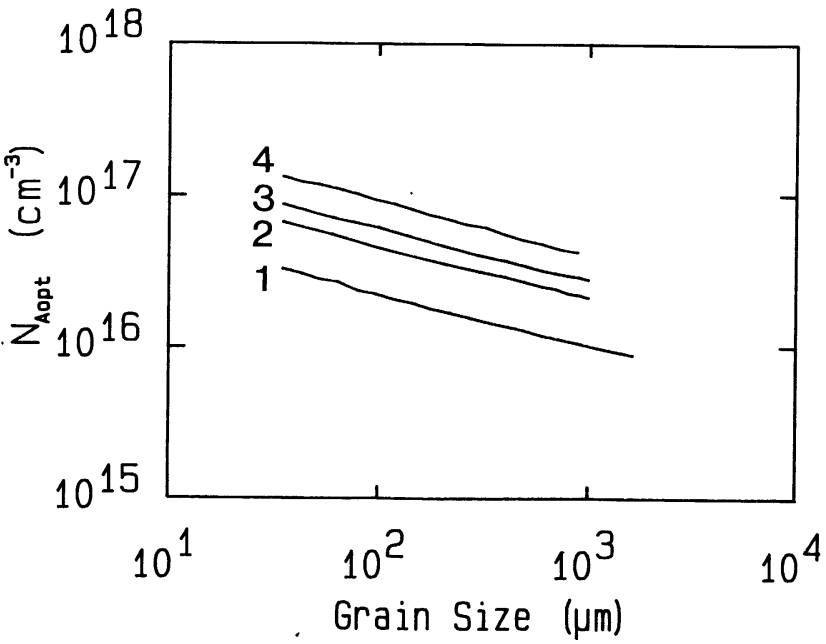

Fig. 7. - Optimum base doping concentration as a function of the grain size, for different interface state densities :

1) $N_{\mathrm{t}}=3 \times 10^{11} \mathrm{~cm}^{-2}$; 2) $N_{\mathrm{t}}=5 \times 10^{11} \mathrm{~cm}^{-2}$;3) $N_{\mathrm{t}}=$ $6 \times 10^{11} \mathrm{~cm}^{-2}$; 4) $N_{\mathrm{t}}=8 \times 10^{11} \mathrm{~cm}^{-2}$;

Base width : $W_{\mathrm{b}}=370 \mu \mathrm{m}$.

Emitter: n-type, $N_{\mathrm{D}}=5 \times 10^{19} \mathrm{~cm}^{-3}, W_{\mathrm{e}}=0.2 \mu \mathrm{m}$.

- as $g$ increases or $N_{\mathrm{t}}$ decreases, $N_{\mathrm{A} \text { opt }}$ tends to the optimum doping concentration of a single-crystal cell, i.e. $3 \times 10^{15} \mathrm{~cm}^{-3}$ for the parameters given in the caption.

- linear and parallel graphs are found, for $g<1 \mathrm{~mm}$, in the log-log diagram of figure 7 so that a very simple numerical expression can be given to calculate $N_{\text {A opt }}$ in so far as the grain size $g$ and the interface state density $N_{\mathrm{t}}$ are known :

$$
N_{\text {A opt }}=10 N_{\mathrm{t}}^{1.4} g^{-0.35} \text { (CGS units). }
$$

The variation of the corresponding maximum efficiency is plotted in figure 8 . It can be noticed that good efficiency levels $(\eta>12 \%)$ can be obtained, even with small grain materials $(g=35 \mu \mathrm{m})$ and very active grain boundaries $\left(N_{\mathrm{t}}=8 \times 10^{11} \mathrm{~cm}^{-2}\right)$ on condition that the base of the cell be doped at the optimum level.

The relation between the optimum doping level $N_{\text {A opt }}$, the grain size $g$ and the interface state density $N_{\mathrm{t}}$ can be particularly useful to engineers who want to improve the performances of solar cells realized on a given polycrystalline silicon on condition that :

i) the shape and the dimensions of the grains are not too different from one another, which allows to define a significant « mean grain size $\bar{g}$ » to be used instead of $g$.

ii) an average value $\bar{N}_{\mathrm{t}}$ representative of the different gb interface state densities can be introduced.

So, despite the recombining activity of grain

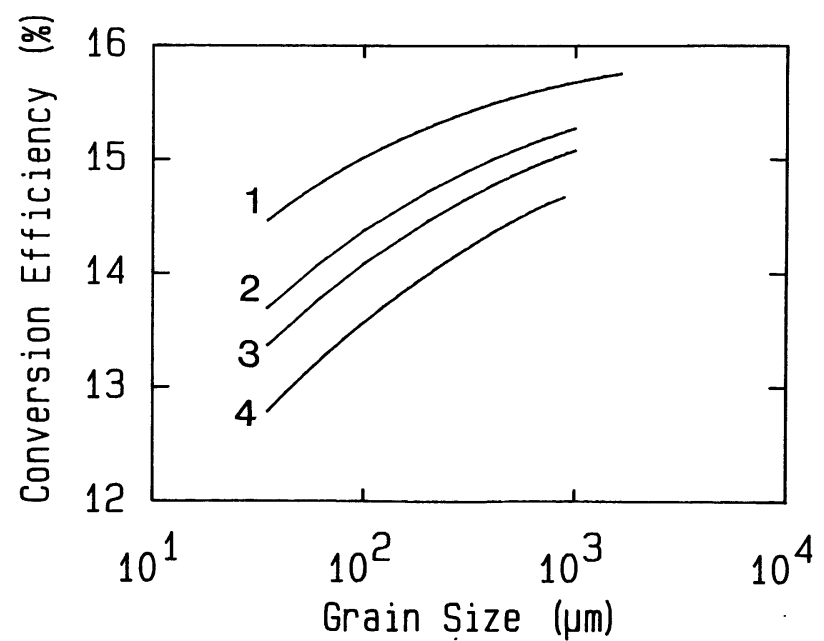

Fig. 8. - Maximum conversion efficiency as a function of the grain size when the base doping concentration is optimized, for different interface state densities :

1) $N_{\mathrm{t}}=3 \times 10^{11} \mathrm{~cm}^{-2}$; 2) $N_{\mathrm{t}}=5 \times 10^{11} \mathrm{~cm}^{-2}$; 3) $N_{\mathrm{t}}=$ $6 \times 10^{11} \mathrm{~cm}^{-2}$; 4) $N_{\mathrm{t}}=8 \times 10^{11} \mathrm{~cm}^{-2}$;

Base width : $W_{\mathrm{b}}=370 \mu \mathrm{m}$.

Emitter: n-type, $N_{\mathrm{D}}=5 \times 10^{19} \mathrm{~cm}^{-3}, W_{\mathrm{e}}=0.2 \mu \mathrm{m}$.

boundaries, good efficiency levels can be obtained with polycrystalline silicon solar cells in so far as the base doping level is optimized. The present limitations of the efficiency of cast or ribbon silicon solar cells might be due to intragrain defects which reduce the grain diffusion length or to the intergranular diffusion of impurities which enhances leakage currents.

As the optimum doping level is high, the substrate thickness can be reduced since the diffusion length is smaller; so, the cost of the photocells may be lowered. Moreover, as a consequence of both high doping concentration and thin substrate, the series resistance is reduced, which is favourable for high excitation (greater than one sun) in particular.

\section{Effective diffusion length and photovoltaic proper- ties.}

In polycrystalline silicon, an «effective diffusion length " is often defined in order to take into account the grain boundary recombination. By means of this concept of effective quantities, an « equivalent monocrystalline cell» (EMC) can be defined as a cell whose diffusion length would be equal to this theoretical effective diffusion length or to a measured one $[22,23]$. The photovoltaic properties of the polycrystalline cell are then assumed to be the same as those of the EMC.

The purpose of the present section is to determine to what extent the EMC model can be used in order to calculate the photovoltaic properties from the 
measurement of an effective diffusion length $L_{\text {eff }}$ in polycrystalline silicon $[3,5]$ by means of the Surface PhotoVoltage (SPV) method [24]. This forecast is very important since this measurement is relatively easy and does not need the full realization of a solar cell which is arduous and expensive.

It can be seen in figure 9 that the plot of the reverse of the quantum efficiency $Q$ as a function of the reverse of the absorption coefficient $\alpha$ computed with our model is linear for polycrystalline silicon as well as for monocrystalline silicon. Under this condition, an effective diffusion length $L_{\text {eff }}$ can be defined as the intercept with the $x$-axis of the straight line $1 / Q=f(1 / \alpha) . L_{\text {eff }}$ depends on the grain size, in particular.

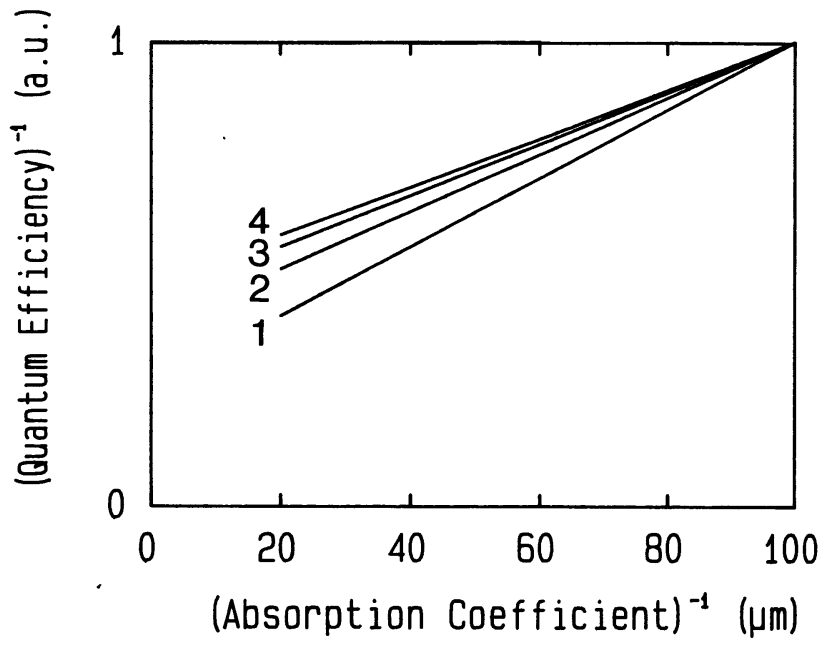

Fig. 9. - Variation of the inverse of the quantum efficiency as a function of the inverse of the absorption coefficient.

Base : p-type, $N_{\mathrm{A}}=10^{16} \mathrm{~cm}^{-3}, W_{\mathrm{b}}=500 \mu \mathrm{m}$.

Emitter : n-type, $N_{\mathrm{D}}=5 \times 10^{19} \mathrm{~cm}^{-3}, W_{\mathrm{e}}=0.2 \mu \mathrm{m}$.

G.b. effective recombination velocity $S=10^{6} \mathrm{~cm} / \mathrm{s}$.

Bulk diffusion length $L_{\mathrm{n}}=100 \mu \mathrm{m}$.

Grain size and effective diffusion length :

1) $g=100 \mu \mathrm{m} ; L_{\mathrm{eff}}=19.9 \mu \mathrm{m}$. 2) $g=200 \mu \mathrm{m} ; L_{\mathrm{eff}}=$ $35.7 \mu \mathrm{m}$. 3) $g=500 \mu \mathrm{m}$; $L_{\mathrm{eff}}=63.6 \mu \mathrm{m}$. 4) $g=2 \mathrm{~mm}$; $L_{\text {cff }}=92.4 \mu \mathrm{m}$.

The relation between this effective diffusion length and the photovoltaic properties has been computed for different values of the material parameters (grain size, bulk diffusion length, effective grain boundary recombination velocity, doping level) [25]. The influence of grain boundaries on $L_{\text {eff }}$ when the grain size is small with respect to the bulk diffusion length is obvious in figure 10 where $L_{\text {eff }}$ is plotted as a function of the ratio $g / 2 L_{n}$ for different bulk diffusion lengths.

Figue 11 shows the variation of the conversion efficiency as a function of the effective diffusion

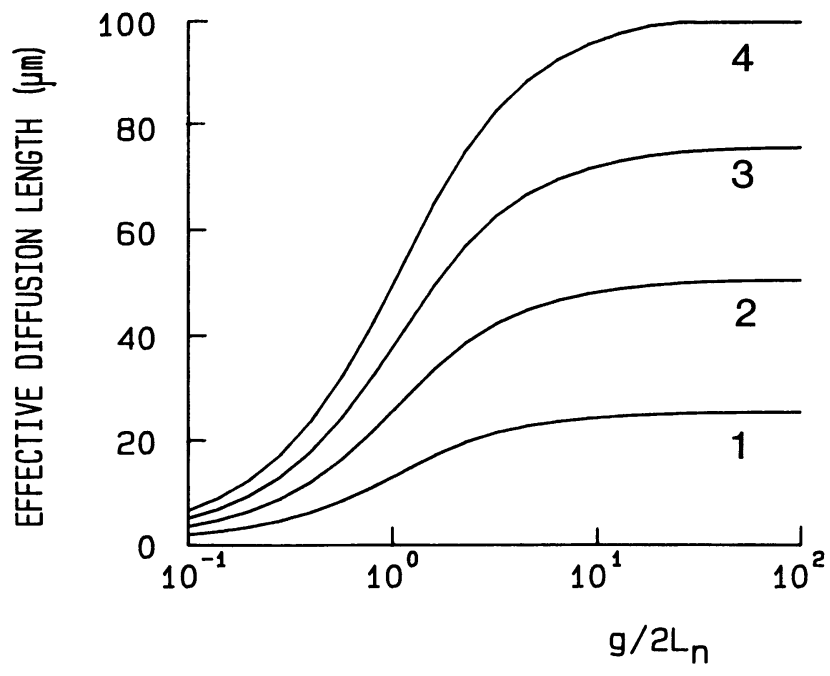

Fig. 10. - Effective diffusion length $v s$ the ratio grain size/bulk diffusion length. $N_{\mathrm{A}}=10^{16} \mathrm{~cm}^{-3} ; W_{\mathrm{b}}=$ $500 \mu \mathrm{m} ; W_{\mathrm{c}}=0.2 \mu \mathrm{m} ; S_{\text {eff }}=10^{6} \mathrm{~cm} / \mathrm{s}$.

1) $L_{\mathrm{n}}=25 \mu \mathrm{m}$; 2) $L_{\mathrm{n}}=50 \mu \mathrm{m}$; 3) $L_{\mathrm{n}}=75 \mu \mathrm{m}$; 4) $L_{\mathrm{n}}=100 \mu \mathrm{m}$.

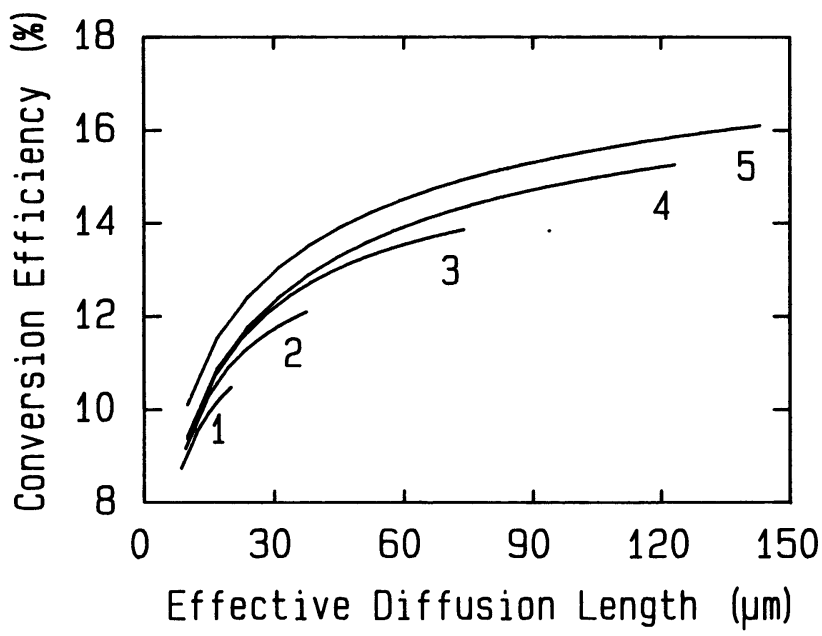

Fig. 11. - Variation of the conversion efficiency as a function of the effective difusion length, for different grain sizes :

1) $g=100 \mu \mathrm{m}$; 2) $g=200 \mu \mathrm{m}$; 3) $g=500 \mu \mathrm{m}$; 4) $g=2 \mathrm{~mm} ; 5)$ equivalent monocrystalline cell (EMC). Base : p-type, $N_{\mathrm{A}}=10^{16} \mathrm{~cm}^{-3}, W_{\mathrm{b}}=500 \mu \mathrm{m}$.

Emitter : n-type, $N_{\mathrm{D}}=5 \times 10^{19} \mathrm{~cm}^{-3}, W_{\mathrm{e}}=0.2 \mu \mathrm{m}$. G.b. effective recombination velocity $S=10^{6} \mathrm{~cm} / \mathrm{s}$.

length, in the case of very active grain boundaries characterized by an effective recombination velocity $S=10^{6} \mathrm{~cm} / \mathrm{s}$. In order to get a variation in the effective diffusion length, the «bulk » diffusion length has been varied from $10 \mu \mathrm{m}$ to $150 \mu \mathrm{m}$, for different values of the grain size $g(g=100,200$, $500 \mu \mathrm{m}$ and $g=2 \mathrm{~mm}$ ). Curve 5 has been calculated in the case of the equivalent monocrystalline cell (EMC), i.e. whose diffusion length is equal to $L_{\text {eff }}$. 
Note that the curves 1-3 cannot be extrapolated to greater effective diffusion lengths since $L_{\text {eff }}$ is limited for a given grain size [25].

The most important remark is that there is not a one to one relation between the effective diffusion length and the photovoltaic quantities. The relation between these quantities depends on all the parameters introduced in this study, i.e. the grain size, the bulk diffusion length, the g.b. recombination velocity, the grain doping level... The dispersion of the experimental results concerning the measurements of the short-circuit photocurrent as a function of the effective diffusion length $[3,6]$ must not be only ascribed to experiment errors ; it can be at least partly explained by this theoretical result.

The values of the EMC photovoltaic quantities are always more optimistic than the corresponding values computed by means of the 3D-model. The EMC short-circuit photocurrent can be greater than the computed photocurrent by about $7 \%$, whereas the EMC dark saturation current can be smaller by a factor of 2 [22]. The shift in the open circuit voltages is relatively small because of the logarithmic dependence of $V_{\text {oc }}$ on the currents, but the EMC conversion efficiency can be overestimated by about 1.5 point if the grain size is small with respect to the bulk diffusion length $L_{\mathrm{n}}$ (Fig. 10). For a given effective diffusion length $L_{\text {eff }}$, the shift is all the more smaller that the grain size is larger and the bulk diffusion length is smaller, i.e. as the ratio $g / L_{\mathrm{n}}$ is greater.

Note that small effective diffusion lengths can be due either to small bulk diffusion lengths or to small grain sizes. In the first case, the EMC-model is able to give a good approximation of the photovoltaic properties whereas in the second case the EMCmodel gives only a coarse estimation.

So, it follows from this study that the EMC model can be useful for the metallurgist as a first test of the ingots, particularly for large grain materials like Silso-Wacker silicon or CGE-Polyx silicon, for which the grain size is typically greater than 1 or $2 \mathrm{~mm}$ and bulk diffusion lengths are close to $100 \mu \mathrm{m}$.

\section{Conclusion.}

A self-consistent formulation of the gb barrier height and the subsequent gb effective recombination velocity versus the excitation level has been established, using the Shockley-Read-Hall theory of carrier recombination-generation phenomena. The variation of the quasi-Fermi level of the minority carriers has been determinated and taken into account and it has been analytically demonstrated that the effective recombination velocity is limited to nearly $v_{\text {th }} / 2$.

The computation of the photovoltaic properties of polycrystalline silicon solar cells with fibrously oriented grains has been done by means of a 3Dmodel. It has been shown that grain boundaries are not an insuperable obstacle to the realization of good efficiency cells on condition that the doping level of the base be optimized in terms of grain size and interface state density. The variation of the optimum doping level as a function of grain size has been given for different interface state densities. A numerical relation is proposed in order to compute this optimum doping level easily.

It has been demonstrated that an effective diffusion length taking into account the recombination at the grain boundaries can be defined in polycrystalline silicon. The measurement of this effective diffusion length by the Surface PhotoVoltage method is able to give easily an upper limit of the performances one can expect from a polycrystalline material. This limit can be approached when the ratio $g / L_{\mathrm{n}}$ (grain size/bulk diffusion length) is greater than 10 . When this ratio is smaller, achieving a good accuracy requires the use of a 3D-model as developed here.

\section{References}

[1] Matare, H. F., Defect Electronics in Semiconductors, (Wiley Interscience, New York) (1971).

[2] Seager, C. H., Ginley, D. S. and Zook, J. D., Appl. Phys. Lett. 36 (1980) 831.

[3] SOPORI, B. L., Role of Electro-optics in Photovoltaic Energy Conversion, Meeting of the Society of Photooptical Inst. Eng., San Diego, California, (edited by S. K. Deb Washington), 1980.

[4] Zehaf, M., Amzil, H., Crest, J. P., Mathian, G., Gervais, J., Martinuzzi, S. and Qualid, J., Proceedings of the Electrochemical Society, 161st Meeting, Montreal (1982).

[5] Mathian, G., Amzil, H., Zehaf, M., Crest, J. P., Martinuzzi, S. and OuAlid, J., Solid State Electron. 26 (1983) 131.
[6] Amzil, H., Zehaf, M., Crest, J. P., Psaila, E., Martinuzzi, S. and OuAlid, J., Solar Cells 8 (1983) 269.

[7] CARD H. C. and YANG, E. S., IEEE Trans. Electron. Devices ED-24 (1977) 397.

[8] Singal, C. M. and PrasAd, B., Int. J. Electron. (1982).

[9] Seager, C. H., J. Appl. Phys. 52 (1981) 3960.

[10] Dugas, J., Thèse de Doctorat d'Etat, Université Aix-Marseille 3 (1985).

[11] Shockley, W., Phys. Rev. 91 (1953) 228.

[12] Marklund, S., Phys. Status Solidi B 85 (1978) 673.

[13] Oualid, J., Singal, C. M., Dugas, J., Crest, J. P. and AmzIL, H., J. Appl. Phys. 55 (1984) 1195. 
[14] Dugas, J., Ali-Mehidi, A. and Oualid, J., Mat. Res. Soc. Europe Meeting, Strasbourg (1984).

[15] Dugas, J. and OuAlid, J., 6th European Photovoltaic Solar Energy Conference, London (1985).

[16] Dugas, J., Crest, J. P., Singal, C. M. and OuAlid, J., Solid State Electron. 26 (1983) 1069.

[17] Green, M. A., Solid State Electron. 21 (1978) 1139.

[18] Hovel, H. J., Solar Cells, (Academic Press, New York) 1975.

[19] ADLER, SMITH and LONGINI, Introduction to semiconductor physics, (Wiley, New York) 1964.

[20] Fossum, J. G., Solid State Electron. 19 (1976) 269.
[21] DuCAs, J. and OuALID, J., Modelling of base doping concentration influence in polycrystalline silicon Solar Cells 20 (1987) 145.

[22] Daud, T., Koliwad, K. M. and Allen, F. G., Appl. Phys. Lett. 33 (1978) 1009.

[23] Koliwad, K. M. and DAUD, T., 14th IEEE Photovoltaic Spec. Conf., San Diego (1980).

[24] A.S.T.M. Standard Test Method F391-78.

[25] Dugas, J. and OuAlid, J., A model of the dependence of the photovoltaic proterties on the effective diffusion length in polycrystalline silicon, Solar Cells 20 (1987) 167. 